\title{
Discussion: Toddlbrook reservoir reports and presentations
}

Nick Reilly BSc(Eng), CEng, FICE

(nick.reilly1@ntlworld.com)

I refer to the reports by Dr. P. Mason (Balmforth, 2020) and Dr. A. Hughes (Hughes, 2020), and their presentations given by webinars in September 2020 .

The two reports on the failure present a very full analysis of the spillway failure of $31 \mathrm{July} / 1$ August 2019 and broadly agree, with minor differences, on the cause and mechanism of failure of the spillway chute. The two mechanisms presented are not mutually exclusive and I would suggest that both are likely to have played a part. It is inconceivable to me that there has been no flow under the spillway slabs in the absence of a cut-off over the long period of time since its construction.

The two reports also agree that the design of the auxiliary overflow was inadequate which may be regarded as an understatement. In view of the requirement of item 2 of the Defra terms of reference to 'assess the dam's capacity pre 1 August to survive extreme flood events without collapse' it is disappointing that more attention was not given to other serious defects of the design.

The converging alignment of the left side training wall, for no apparent reason other than, perhaps, to encourage spill flow to progress down the stream, is a major defect. As any hydraulics specialist knows, it is extremely difficult to divert supercritical flows and the tendency at high discharges will be for the flow to leap over the wall. This would cause erosion of the downstream slope of the dam and ultimately lead to failure of the embankment. The reports give no estimate of the peak flow down the chute during the event but it was stated to be only a fraction of the predicted probable maximum flood (PMF) flow for which it should have been designed. In 1998 it was reported that the left wall (prior to raising) was overtopped at $15 \mathrm{~m}^{3} / \mathrm{s}$. The peak flow over the auxiliary spillway during the predicted PMF event is estimated at $164 \mathrm{~m}^{3} / \mathrm{s}$. There is no evidence that the wall raising was model tested to confirm its adequacy.

The reports are silent on the arrangements for energy dissipation at the toe of the spillway chute. No information is given about any form of stilling basin and it appears to be just an armoured section of the channel. Flow of $164 \mathrm{~m}^{3} / \mathrm{s}$ at about $20 \mathrm{~m} / \mathrm{s}$ has a huge amount of energy and definitely requires carefully designed dissipation measures. The Defra report refers to a scour hole at the downstream end of the 'stilling basin' in 1988 arising from a flow of only $15 \mathrm{~m}^{3} / \mathrm{s}$.

Other features which indicate a lack of understanding of basic hydraulics on the part of the 1970 designers include the sharp edge in the invert at the top of the chute and the inclusion of plums and granite chippings in the concrete of the chute. The inclusion of these features in the chute slab would cause negligible energy dissipation at high flows and, as the Defra report notes, the plums have undesirable side effects.

It would appear from the foregoing that the design of the auxiliary spillway was not fit for purpose and it would definitely have failed in one way or another at high flows. It is of concern that the design in 1970 was overseen by two panel 1 engineers (1930 Act) and that a succession of subsequent inspecting engineers failed to identify obvious deficiencies.

One questioner in the discussion asked if panel engineers had adequate knowledge of spillway hydraulics and Dr Mason responded that he thought so. Up to the time of this incident I would have agreed but the fact that a succession of panel engineers, including the original designers, have not questioned the obvious design flaws at Toddbrook rather casts doubt on this. I recall that a lack of understanding of hydraulic factors contributed to the Ulley incident some years ago. We do not seem to be drawing the obvious conclusion that some panel engineers are not up to the job, a conclusion that an independent reviewer of the reports could hardly avoid coming to.

There were suggestions in the webinar discussion that maybe some changes to the Act or related procedures such as frequency of inspection be implemented. I think that this misses the point. The reservoir safety system in this country, of which we are justly proud, depends on the expertise and dedication of $\mathrm{AR}$ panel engineers backed up by supervising engineers. It 
seems to me that we have to address the training and examining of prospective panel engineers as a matter of urgency. Perhaps a written test and/or much longer interview process would be appropriate. If this is addressed, I see absolutely no need for changes to legislation or procedures.

\section{REFERENCES}

Balmforth D (2020) Toddbrook Reservoir Independent Review Report. Defra, London, UK.

Hughes AK (2020) Report on the Nature and Root Cause of the

Toddbrook Reservoir Auxiliary Spillway. Canal and River Trust, Milton Keynes, UK. 